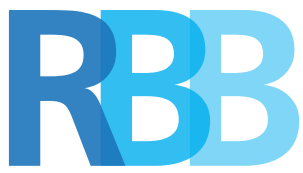

Revista Brasileira de Bioética

Livia Penna Tabet

Cátedra Unesco/Programa de Pós-Graduação em Bioética da UnB Brasília, Distrito Federal, Brasil liviapenna@gmail.com

Volnei Garrafa

Cátedra Unesco/Programa de Pós-Graduação em Bioética da UnB Brasília, Distrito Federal, Brasil garrafavolnei@gmail.com

\section{Fim da vida: morte e eutanásia}

\section{End of life: death and euthanasia}

Resumo: A morte é considerada a maior adversária dos profissionais de saúde, sobretudo dos médicos, que a vêem como falha. Hoje, com os recursos tecnológicos existentes, pode ser possível prolongar a vida por tempo indefinido, em ambientes como as Unidades de Terapia Intensiva, muitas vezes sem levar em consideração a vontade do doente e/ou de seus familiares. As questões relacionadas à morte transpassam os limites individuais e familiares, abrangendo os campos religioso, ético e legal. Neste contexto, a eutanásia é um dos temas que gera polê mica e reflexão sob o ponto de vista bioético. As discussões bioéticas acerca da eutanásia se baseiam nos princípios do respeito à autonomia/qualidade de vida (defensores) e da sacralidade da vida (opositores). O presente artigo tem como objetivo revisar conceitos da morte e da eutanásia, em diferentes perspectivas (histórica, religiosa, legal, entre outros), além de abordar os conceitos de distanásia, ortotanásia, mistanásia e cuidados paliativos. Por fim, discutir e refletir aspectos bioéticos da eutanásia.

Palavras-chave: fim da vida; eutanásia; morte; bioética.

Abstract: Death is considered the biggest opponent of health professionals, especially doctors, who see it as failure. Today, with the technology resources available, it may be possible to prolong life indefinitely in environments such as the Intensive Care Units, often without taking into consideration the will of the patient and/or their families. The issues related to death trespass individual and family limits, including the religious, ethical and legal fields. In this context, one of the themes that generate great controversy and bioethical reflection is related to euthanasia. Bioethical discussions about euthanasia are based on the principles of respect for autonomy/quality of life (defenders) and the sacredness of life (opponents). This article aims to review concepts of death and euthanasia in different perspectives (historical, religious, juridical, among others), and address the concepts of dysthanasia, orthothanasia, mysthanasia and palliative care. Finally, it discusses and reflects on the bioethical aspects of euthanasia.

Keywords: end of life; euthanasia; death; bioethics. 


\section{Introdução}

$\mathrm{N}$

século XX e nas últimas décadas, o crescimento tecnológico-científico no âmbito da saúde proporcionou uma mudança radical na forma do cuidado com os pacientes, com o surgimento de fármacos anestésicos, analgésicos e antibióticos; o aprimoramento de técnicas cirúrgicas, o desenvolvimento de equipamentos, ambientes como as Unidades de Terapia Intensiva (UTI) e novas terapias que oferecem suporte avançado de vida, com consequente redução nas taxas de mortalidade, morbidade e aumento na expectativa de vida (Boeuri, 2010).

A cada dia, surgem recursos avançados tanto para diagnosticar precocemente uma doença quanto para tratá-la, sendo possível prolongar a vida por tempo indefinido, seja artificialmente ou não, com auxilio de modernos e onerosos equipamentos (respiradores artificiais, máquinas de diálise, de circulação extracorpórea, além dos inúmeros medicamentos) (Boeuri, 2010). Com isso, torna-se mais difícil o ideário da "morte natural", ou seja, vivenciar a morte o mais naturalmente possível, como um evento que faz parte do ciclo da vida.

De maneira geral, a morte é considerada a maior adversária dos profissionais de saúde, sobretudo dos médicos, resultando em uma luta desenfreada pela manutenção da vida a qualquer preço. Tal conduta pode trazer agonia, dor e sofrimento prolongado, seja do doente e/ou dos familiares (Batista, 2007). Paradoxalmente, em razão dos avanços tecnológicos da medicina, cada vez mais se fala no medo de não poder partir no momento em que o corpo e a mente pedem o descanso final, mesmo quando estes se encontram em grande sofrimento (Sameshima, 2012). Segundo Vasconcelos, Inamura e Villar (2011), nesse contexto, surgem algumas indagações: até quando é ético prolongar ou abreviar uma vida? Como devemos lidar com o doente em condição dolorosa e irremediável, e que deseja morrer? Além disso, até que ponto o doente tem o direito de intervir, opinar e ser ouvido em relação à sua própria morte? As questões relacionadas à morte, na maioria das vezes, transpassam os limites individuais e familiares, abrangendo os campos religioso, ético e legal. O presente artigo tem como objetivo revisar conceitos da morte e da eutanásia, em diferentes perspectivas (histórica, religiosa, legal, entre outros), além de abordar os conceitos de distanásia, ortotanásia, mistanásia e cuidados paliativos. Por fim, discutir e refletir aspectos bioéticos da eutanásia.

\section{A morte}

Tal como o nascimento, a fome ou a sede, a morte é inexorável e natural. Diante dela, os homens se igualam, e são nivelados ao mesmo destino (Maranhão, 1998). A morte pode ser caracterizada como "biológica" e "clínica", onde a primeira é ocasionada em células, tecidos e órgãos, individualmente, até o comprometimento total do organismo, e a segunda corresponde ao critério utilizado pela medicina e pelo direito para definir a morte do indivíduo como um todo. A "morte clínica" antecede a "morte biológica", pois a deterioração celular total pode ocorrer bem mais tarde em relação ao fim da pessoa (Villas-Bôas, 2005). 
Com o desenvolvimento de técnicas de substituição de órgãos, medidas de suporte em terapia intensiva e o prolongamento da vida através de métodos artificiais, tornou-se fundamental a distinção entre a morte biológica e a encefálica. Em 1969 a sociedade americana de eletroencefalografia publicou critérios para definir a morte encefálica, e em 1978, a American Bar Association definiu a mesma como a "cessação irreversível das funções totais do cérebro, de acordo com os padrões costumeiros da prática médica". Em 1981, os testes circulatório e respiratório foram incorporados para a determinação da morte (Engelhardt, 2004). Sendo assim, a morte encefálica é a abolição total e irreversíve/ das funções do encéfalo, com estado de coma irreversível; e após a falência do encéfalo, em algumas horas ou dias deixam de funcionar também os outros sistemas, como o circulatório e o respiratório (Kovacs, 2003).

Para Kovacs (2003), do ponto de vista psicossocial, pode-se falar na morte em vários níveis: físico, psicológico ou social; entretanto, o critério de morte, tem de ser único e preciso. A definição do momento de morte, além de garantir os rituais fúnebres a quem de fato morreu, se reveste de grande importância para se estabelecer o momento de retirada de órgãos para fins de transplante.

No Brasil, o Conselho Federal de Medicina (CFM), por meio da Resolução n. 1.480 de 1997, apresentou os parâmetros para a caracterização da parada total e irreversível das funções encefálicas em pessoas com mais de dois anos de idade, através da avaliação clínica (coma aperceptivo com ausência de atividade motora supraespinal e apneia); e de exames complementares (ausência de atividade elétrica cerebral ou, ausência de atividade metabólica cerebral ou, ausência de perfusão sanguínea cerebral) (Brasil, 1997).

Atualmente, a morte encefálica é considerada o critério mais seguro para confirmar a morte de uma pessoa. Nessa situação, o indivíduo pode apresentar circulação sanguínea e batida do coração e, ainda assim, ser dado como morto. Sendo assim, extintas as funções do tronco encefálico, o suporte terapêutico empregado pode ser suspenso, sem que se configure a prática de eutanásia (Sameshima, 2012). No entanto, para alguns autores, os instrumentos para avaliar a morte encefálica podem não ser precisos, como no caso do eletroencefalograma, um exame clássico, mas que pode apresentar distorções (Kovacs, 2003).

\section{A morte ao longo da história}

O conceito de morte se transformou ao longo dos séculos, influenciado por diversos fatores como a cultura de uma sociedade, a religião e os valores éticos e morais de seus indivíduos. Nos tempos modernos, já não se morre como antigamente: a morte esperada no leito, os últimos desejos, a despedida da família reunida, com as crianças presentes. Na sociedade tecnológica de hoje, a morte é institucionalizada; morrer é algo distante, que acontece no hospital, e o paciente terminal frequentemente já está inconsciente, em uma UTI (Horta, 1999). 
Nas sociedades primitivas, a morte era vista como o resultado de uma intervenção estranha maléfica, o mau-olhado de um vizinho invejoso ou uma feiticeira; um ancestral que retornou para buscá-lo, ou mesmo um gato preto em seu caminho (Illich apud Herzog, 1960). Ivan Illich (1975), em seu livro Nêmesis da Medicina - A expropiração da saúde, faz uma retrospectiva sobre a concepção da morte pelo homem ao longo dos últimos cinco séculos, que passou por distintos estágios:

a. A Dança dos Mortos, no século XIV: a dança dos mortos e sobre seus túmulos, com canções e poemas eróticos, significava a proclamação da alegria de estar vivo. Já no final do mesmo século, o encontro entre os vivos e os mortos passou a se dar através de uma meditação introspectiva. Neste período, o médico raramente está presente, a morte o trata como um colega.

b. A Dança Macabra (conduzida por um esqueleto): no período da Renascença, a vida após a morte não é mais o prolongamento da vida terrena, mas sim a divisão do inferno, visto como um castigo; e o paraíso, visto como dom divino. A morte não é mais o objetivo da vida, é o fim. Na dança macabra, o médico é objeto das zombarias do esqueleto. Nos séculos XV e XVI, a literatura médica assinala dois deveres opostos para o médico: ajudar a curar ou, ao contrário, suavizar e acelerar a morte.

c. A morte burguesa: aqueles que possuem recursos começam a pagar para fazer a morte recuar; inicia-se o prolongamento da vida. O novo tipo de paciente é um homem rico, que se recusa a morrer. O aparecimento da morte natural abriu caminho também para novas atitudes em face da morte e da doença, que iam se expandir no fim do século XVII. Durante toda a Idade Média, o corpo humano tinha sido sagrado; agora, o médico começa a dissecar cadáveres, antes proibido. Deu-se início ao valor social da velhice, onde a sabedoria era atribuída unicamente à idade.

d. A morte clínica: O período se caracterizou como a batalha travada pelo médico contra a fome e a peste no século XIX. A capacidade de sobreviver por muito tempo, à recusa de ceder diante da morte e a intervenção médica, mesmo nos casos incuráveis, fez nascer uma nova concepção da doença, que se tornou o tipo de saúde ao qual a velhice podia aspirar.

e. A medicina, na pessoa do médico, rico de formação científica, se interpõe entre o paciente e sua morte, no século XX, fazendo com que a morte perdesse a imediaticidade e a intimidade que havia adquirido quatro séculos antes. A força da natureza, celebrada com a morte, é transformada em uma legião de causas clínicas específicas em todo o mundo. A esperança de que os médicos podiam tratar doenças específicas deu lugar ao mito de seu poder contra a morte. A nova imagem da morte justificou um novo grau de controle social: a sociedade tornou-se responsável pela prevenção da morte de cada um de seus membros; o tratamento médico, eficaz ou não, tornou-se um dever. Para Pessini (2001), 
"atualmente, a medicina trabalha com vistas ao futuro, procurando promover uma vida boa, saudável, aumentar o tempo de vida e sua qualidade. A morte é admitida com relutância no âmbito da medicina, como o limite para atingir tais objetivos. É sentida como falha".

\section{Eutanásia}

O homicídio com consentimento é relatado desde as mais antigas civilizações, inclusive na Bíblia. O surgimento do cristianismo introduziu o conceito de sacralidade da vida, ou seja, a vida como um dom de Deus a ser preservado e cultivado, e ninguém mais tinha o direito de reivindicar para si o domínio sobre a sua vida ou a de outros (Horta, 1999). Logo, a sacralidade da vida consiste em uma concessão da divindade, e não pode ser interrompida mesmo por expressa vontade de seu detentor (SiqueiraBatista e Schramm, 2005).

A eutanásia, tida como "boa morte" (eu = bom e thanatos = morte), significa "dar a morte, por compaixão, a alguém que sofre intensamente em estágio final de doença incurável ou que vive em estado vegetativo permanente" (Engelhardt, 2004). Na mitologia grega, Thanatos era o deus representativo do falecimento, filho da noite e irmão de Hypnos, deus do sono. A eutanásia expressa a morte sem dor, sem sofrimento; a morte piedosa e digna (Moura, 2007). Em termos contemporâneos, a eutanásia poderia ser conceituada como: "o emprego ou abstenção de procedimentos que permitem apressar ou provocar o óbito de um doente incurável, a fim de livrá-lo dos extremos sofrimentos que o assaltam" (Lepargneur, 1999).

Até o século XVII, a eutanásia se referia aos meios para se alcançar a morte boa ou a morte fácil, pela aceitação da própria mortalidade (Horta, 1999). A concepção de eutanásia vista como um ato da medicina é oriunda do pensamento de Francis Bacon, que, em 1623, escreveu em seu livro Historia vitae et mortis: "o médico deve acalmar os sofrimentos e as dores não apenas quando este alívio possa trazer a cura, mas também quando pode servir para procurar uma morte doce e tranquila"(Sameshima, 2012).

O desvio que transformou e desvirtuou a eutanásia em política pública ocorreu no século XX, sedimentando uma conotação marcadamente negativa -, por ocasião do Terceiro Reich na segunda guerra mundial, quando a eutanásia foi relacionada a práticas que não tinham nada a ver com a morte sem sofrimento, e sim ao homicídio, ao suicídio influenciado e ao genocídio (Siqueira-Batista e Schramm, 2005).

A eutanásia pode ser classificada como ativa, passiva e de duplo efeito. Na eutanásia ativa, a morte é provocada de forma deliberada, sem sofrimento ao paciente. Na passiva, a morte ocorre por omissão em iniciar uma ação médica que garanta a perpetuação da vida. Por sua vez, na eutanásia de duplo efeito, a morte é acelerada, consequência de ações médicas com o objetivo de aliviar o sofrimento do paciente (Engelhardt, 2004). 
A eutanásia também pode ser voluntária ou involuntária. Como o próprio nome diz, na primeira, a morte é apressada a pedido do paciente, em plenas condições de decidir por si só. Já na segunda, o ato é realizado por determinação de terceiros, quando o interessado se encontra inconsciente ou incapacitado de se fazer entender (Bomfim, 2009). O suicídio assistido não deve ser confundido com eutanásia, pois apesar da morte ser provocada em ambos, na eutanásia, quem causa a morte ao efetuar uma ação ou omissão é o terceiro, enquanto que no suicídio assistido é o próprio paciente que age na concretização da morte (Lopes, 2011).

Algumas classificações da eutanásia são errôneas, pois falta o seu principal elemento caracterizador, que é a compaixão pelo próximo. Alguns exemplos são a eutanásia eugênica (aprimoramento da raça); a eutanásia criminal (eliminar indivíduos tidos como socialmente perigosos); a eutanásia econômica (levar a óbito pessoas consideradas inúteis e geradoras de grande despesa econômica assistencial); e a eutanásia experimental (eliminar seres humanos para realização de experiências científicas) (Lopes, 2011).

Hoje, a eutanásia é um ato médico cujo propósito é abreviar a vida como única maneira de extinguir um sofrimento insuportável, ocasionado por uma patologia incurável (Ferraz, 2001). Não apenas o sofrimento físico, mas também o psicológico ou moral podem caracterizar uma situação penosa (por exemplo, a dor moral do tetraplégico, a angústia por antecipação do portador de Alzheimer e o padecimento do paciente em estado vegetativo persistente que declara antecipadamente sua preferência pela morte) (Bomfim, 2009). A busca pela eutanásia, muitas vezes, está relacionada ao medo da dor, da solidão, do abandono pelas famílias e pela frieza e impessoalidade que permeiam a assistência de muitos quando próximos à morte (Magalhães et. al., 2013).

\section{Eutanásia e religião}

A maior parte das religiões mais expressivas e difundidas pelo mundo é contrária à prática da eutanásia. Sameshima (2012) fez uma comparação entre o cristianismo, o budismo, o judaísmo e o islamismo sobre o tema. A posição da Igreja Católica é de franca desaprovação, pois acredita que a eutanásia afronta o respeito à pessoa humana e seu bem mais valioso, a vida. Essa afirmação é possível em virtude dos escritos bíblicos e em diversos pronunciamentos oficiais do Vaticano. Em relação ao paciente terminal, no qual o tratamento apenas prolonga um estado de sofrimento contínuo, os católicos sustentam uma opinião mais flexível, permitindo que o paciente opte por deixar-se morrer, seguindo o seu curso natural (Sameshima, 2012). Já os budistas não se opõem à eutanásia ativa e passiva, por dois argumentos: a vida é valiosa, mas não é divina (não há a crença na existência de um deus criador); além disso, os budistas acreditam que a morte deva ser precedida de pensamentos harmoniosos e conscientes, reconhecendo assim o direito dos indivíduos determinarem o instante da mesma (Buzaglo, 2006). 
A posição islâmica frente à eutanásia é de reprovação, dado o caráter inviolável e sagrado da vida e a limitação da autonomia por parte dos adeptos, já que sua vontade está submetida ao cumprimento da vontade maior de seu Deus, dos textos sagrados e documentos que contêm sua interpretação. Segundo o Código Islâmico de Ética Médica: "a vida humana é sagrada e não deve ser retirada voluntariamente. O médico não tirará a vida, mesmo movido pela compaixão" (Sameshima, 2012). A tradição legal judaica proíbe a prática da eutanásia, uma vez que o médico atua na posição de mediador de Deus na preservação da vida. Ao decidir entre a vida ou a morte de um paciente, estaria o profissional da saúde usurpando uma incumbência divina (Sameshima, 2012).

\section{A eutanásia pelo mundo}

A Holanda foi o primeiro país do mundo a legalizar a prática da eutanásia e do suicídio assistido, em 2002. Após a Holanda, no mesmo ano, a Bélgica também autorizou e legalizou a eutanásia. Nos países europeus, apenas a Holanda, a Bélgica e a Suíça têm legislaç̃̃es que tratam especificamente do tema (Batista, 2007). Nos Estados Unidos, a decisão sobre a permissão ou proibição da eutanásia é de competência de cada um dos estados da federação. A eutanásia no país é ilegal, mas alguns estados autorizam o suicídio assistido (Batista, 2007). O Estado de Oregon foi o primeiro a permitir o suicídio assistido no país, em 1997. Hoje, mais cinco Estados permitem a prática do suicídio assistido: Washington, Vermont, Novo México, Montana e Califórnia.

O Uruguai foi o primeiro país do mundo a tolerar a prática da eutanásia. Desde 1934, por meio de seu código penal, o país prevê a possibilidade de o juiz isentar de pena a pessoa que comete o chamado homicídio piedoso. O motivo da eutanásia deverá ser analisado pelo juiz sob três aspectos: quem cometeu ter antecedentes honráveis, o ato ter sido realizado por motivo piedoso e a vítima ter feito reiteradas súplicas. Já o suicídio assistido é tratado como crime no país (Reta e Grezzi, 1996).

A Corte Constitucional da Colômbia aprovou, em 2015, a Resolução no 1216 do Ministério da Saúde e Proteção Social, com as diretrizes para a organização e funcionamento dos Comitês Científico-Interdisciplinares para o direito de morrer com dignidade dos enfermos em fase terminal, assim como o direito aos cuidados paliativos (Republica de Colômbia, 2015). Ainda em 2015, foi realizada na Colômbia, a primeira eutanásia legalizada da América Latina.

No Brasil, de acordo com o código penal vigente, a eutanásia (ativa ou passiva) é crime, podendo ser caracterizada como homicídio ou auxilio ao suicídio, não levando em conta se houve consentimento do paciente e/ou familiares. A Lei Penal prevê a figura do homicídio privilegiado, que se dá quando o agente comete o crime impelido por motivo de relevante valor social ou moral, ou sob o domínio de violenta emoção (compaixão, piedade, etc.) (Brasil, 2011). 
Na história da normatização ética da medicina no Brasil, os códigos seguiram a orientação hipocrática, enaltecendo o papel da medicina na defesa da vida até seu momento final, repudiando a eutanásia. Em 1931, o Código de Deontologia Médica dizia: "o médico não aconselhará nem praticará, em caso algum, a eutanásia", e estabelecia que "um dos propósitos mais sublimes da medicina é sempre conservar e prolongar a vida" (Lopes, 2011). No final de 2006, o Conselho Federal de Medicina emitiu a Resolução 1.805/2006, que permitia ao médico, na fase terminal de enfermidades graves e incuráveis, limitar ou suspender procedimentos e tratamentos que prolongassem a vida do doente, respeitando a vontade do paciente ou de seu representante legal. O doente continuaria a receber todos os cuidados necessários para aliviar os sintomas que levassem ao sofrimento, com assistência integral, conforto físico, psíquico, social e espiritual, inclusive assegurando-Ihe o direito da alta hospitalar (Brasil, 2006).

Em 2010, consolidou-se a aplicação do novo Código de Ética Médica (Resolução CFM 1.931/09). Nele, o caráter antiético da distanásia é reafirmado, mantendo a proibição da eutanásia e do suicídio assistido, porém de maneira mais contundente. A partir deste código, há um tratamento normativo mais apurado no tocante ao conceito de cuidados paliativos e um recrudescimento da autonomia da vontade do paciente (Lopes, 2011). Nos casos de doença incurável e terminal, o médico deve oferecer todos os cuidados paliativos disponíveis, mas sem ações inúteis ou obstinadas, levando sempre em consideração a vontade expressa do paciente ou, na impossibilidade, a de seu representante legal (Vasconcelos, Inamura e Villar, 2011).

O Projeto de Lei n 125/96 foi o único sobre a legalização da eutanásia no Brasil tramitando no Congresso Nacional, porém, jamais foi colocado em votação. O projeto propunha a permissão da eutanásia, desde que uma junta de cinco médicos atestasse o sofrimento físico ou psíquico do doente. O paciente poderia requisitar a eutanásia se estivesse consciente, e no caso de inconsciência, a decisão caberia a seus parentes próximos (Lima Neto, 2003).

\section{Conceitos de distanásia, ortotanásia, mistanásia e cuidados paliativos}

A distanásia, também conhecida como obstinação terapêutica (Europa), ato médico fútil ou futilidade médica/terapêutica (Estados Unidos), caracteriza-se pela utilização de medidas terapêuticas excessivas que não cumprem a finalidade de melhorar ou curar o paciente, ao contrário, com a adoção de medidas fúteis e exorbitantes, o médico prolonga a vida estritamente em termos quantitativos, em detrimento da qualidade (Lopes, 2011). A vida é mantida por meio de tratamentos desproporcionais, levando a um processo de morrer prolongado e com sofrimento físico ou psicológico (Pessini, 2001).

A distanásia parece ser uma prática comum em UTI, visto que a gravidade dos pacientes faz com que a equipe adote uma postura terapêutica "sintomática", que muitas vezes mantém o paciente "clinicamente estável", enquanto, na verdade, o 
processo de morte já foi instalado (Magalhães et. al., 2013). A vida física é considerada o bem supremo e absoluto, acima da liberdade e da dignidade (Horta, 1999). Enquanto a eutanásia enfatiza a qualidade de vida nos instantes finais ao eliminar a dor, a distanásia se atém a prolongar a quantidade de vida ao máximo, encarando a morte como o maior e último inimigo da medicina (Pessini, 2004).

A ortotanásia é a arte da "morte correta", no seu tempo certo (orthos - "correto", e thanatos - "morte"), humana, sem abreviar a vida. Tem como grande desafio o resgate da dignidade do ser humano em seu processo final, com a promoção do bem-estar da pessoa em fase terminal (Magalhães et. al., 2013). Significa o não prolongamento artificial do processo natural da morte, deixando a mesma seguir o seu curso natural, com o consentimento dos pacientes e seus familiares (Borges, 2001).

Portanto, ortotanásia é o procedimento médico que, diante da morte inevitável e iminente do paciente, interrompe o tratamento inútil da doença, que somente prolongaria um sofrimento desnecessário, e conduz à realização de cuidados paliativos que objetivem dignidade no morrer (Santoro, 2011). O questionamento em relação à ortotanásia se dirige ao significado do tempo certo para morrer, e quem poderia determiná-lo, além do seu limite com a eutanásia passiva. Segundo Sameshima (2012), a distinção entre ortotanásia e eutanásia passiva é importante, visto que na ortotanásia não há encurtamento do período vital ou extensão do processo da morte, e sim a suspensão ou limitação de qualquer tratamento fútil, desproporcional ou extraordinário. Logo, o óbito não é buscado, tampouco provocado, pois sua inevitável ocorrência será resultante da própria enfermidade. Na eutanásia passiva, a morte do doente terminal é provocada, pois existe uma conduta médica omissiva quanto aos cuidados paliativos ordinários.

Já a mistanásia (mis - infeliz; thanatos - morte) é a morte pela situação precária de nutrição ou ausência de cuidados médicos e de higiene básicos. Transcende o âmbito puramente médico-hospitalar, incidindo sobre aqueles indivíduos que sequer têm acesso ao atendimento por motivo de carência social, encontrando-se numa situação de ausência de possibilidades econômicas e políticas (Villas-Bôas, 2005). Pode estar relacionada à falta de acesso às condições mínimas de vida, a omissão de socorro de doentes à margem dos sistemas de saúde, aos diferentes tipos de erros médicos, e à prática de eliminação dos indesejados, como no período do Terceiro Reich (Martin, 1998). O grande leque de circunstâncias alcunhadas como mistanásia, e a eventual sobreposição com a ideia de distanásia a torna um conceito problemático nas discussões (Siqueira-Batista e Schramm, 2005).

Os cuidados paliativos utilizam uma abordagem multidisciplinar e enfocam as necessidades físicas, emocionais, espirituais e sociais dos pacientes terminais/familiares. Buscam garantir: que o paciente seja mantido livre de dor tanto quanto possível, de modo que possa morrer confortavelmente e com dignidade; que receba cuidados contínuos, não seja abandonado ou perca sua identidade pessoal; que tenha controle tanto quanto possível quanto às decisões a respeito de seu cuidado e lhe seja dada 
a possibilidade de recusar qualquer intervenção tecnológica prolongadora de vida; que o mesmo seja ouvido em seus medos, pensamentos, sentimentos, valores e esperanças e seja capaz de decidir onde queira morrer (Pessini, 2001).

\section{Reflexões bioéticas acerca da eutanásia}

O século XX trouxe para humanidade a possibilidade de curar muitas doenças e a mudança na percepção da morte. No século XXI, a busca pela imortalidade e o temor pela morte, associados à era da alta tecnologia fez com que surgissem dilemas éticos relacionados aos conceitos de boa morte e morte digna (Batista, Barreto, Miranda e Garrafa, 2009). A bioética, desde a sua origem, sempre esteve inserida nos debates dos processos do nascer e do morrer. Moritz, citado por Batista, Barreto, Miranda e Garrafa (2009), ressalta que hoje a morte tornou-se prolongada, devido ao desenvolvimento tecnológico; científica, pelo aperfeiçoamento da monitorização; passiva, pois as decisões pertencem aos médicos/familiares e não ao enfermo; profana, por não atender às crenças e valores do paciente, e isolada, pois o ser humano morre socialmente em solidão.

Para Sameshima (2012), falar sobre a eutanásia é entrar em território complexo e controverso, pois se trata de matéria multidisciplinar, com aspectos jurídicos e questões subjetivas, como a religião e valores pessoais. Tanto a aceitação quanto a rejeição da eutanásia são sustentadas por argumentos plausíveis, e a polêmica se dá em grande parte pelo tabu da discussão do tema na sociedade ocidental, e pelos sentimentos que as tais questões despertam nas pessoas.

A eutanásia é um tema de grande proeminência nos debates bioéticos, principalmente nos países desenvolvidos, dado o progresso tecnológico alcançado pela medicina nessas sociedades. A preocupação da bioética quanto ao prolongamento da vida se dá em analisar de que forma este avanço do conhecimento científico está em harmonia com a autonomia e a qualidade de vida do indivíduo. Logo, a eutanásia é uma conduta complexa diante da bioética, envolvendo o diagnóstico de morte iminente, paciente terminal, cura impossível, estado agônico, entre outros (Farah, 2011).

Batista, Barreto, Miranda e Garrafa (2009) propuseram tópicos de discussão e reflexão bioética acerca da terminalidade da vida, tais como: 1. A autonomia, o medo da morte e as atitudes diante da morte; 2. A morte digna no contexto de uma vida sofrida e infeliz; 3. Os problemas do sistema de saúde, da mercantilização da medicina, a crescente proletarização do médico; 4 . O diagnóstico da morte e os transplantes de órgãos; a morte nas UTI e a alocação de recursos; 5. Os argumentos de cunho religioso e jurídico; 6. Os paradigmas da medicina e o aumento da longevidade e do número de doenças crônicas degenerativas; 7 . 0 enfraquecimento da relação médico-paciente e da formação do médico quanto aos poucos ensinamentos sobre a morte durante os cursos de medicina.

Para Siqueira-Batista e Schramm (2005), discutir e ponderar sobre a moralidade da eutanásia, demarcando-se adequadamente os conceitos e enfocando-se os ar- 
gumentos favoráveis e contrários à sua realização, torna-se premissa crucial para um amplo exercício da cidadania. As discussões bioéticas sobre a eutanasia repousam entre os princípios do respeito à autonomia (defensores) e o da sacralidade da vida (opositores) (Siqueira-Batista e Schramm, 2008).

Para Batista (2007), é insuficiente analisar um tema tão polêmico unicamente sob o ponto de vista da bioética principialista de Georgetown, baseada nos princípios de autonomia, justiça, beneficência e não maleficência. Ao analisarmos os dilemas éticos sob a perspectiva da declaração universal da bioética e dos direitos humanos (DUBDH, 2005), os seguintes artigos podem ser citados: respeito à dignidade humana, aos direitos humanos, e às liberdades fundamentais em sua totalidade (Art. $3^{\circ}$ ); maximização dos efeitos benéficos diretos e indiretos para os doentes na aplicação e no avanço dos conhecimentos científicos, da prática médica e das tecnologias (Art. $4^{\circ}$ ); respeito à autonomia das pessoas quanto à tomada de decisões (Art. $5^{\circ}$ ); proteção aos indivíduos e grupos particularmente vulneráveis, e respeito à sua integridade pessoal (Art. $\left.8^{\circ}\right)$.

Hipócrates, em seu juramento, cita: "a ninguém darei, para agradar, remédio mortal, nem conselho para induzir à perdição". Logo, seguindo o juramento hipocrático, há quem defenda que a eutanásia subverta a doutrina, depreciando o valor da prática medica ao dar fim à vida de um paciente. Para os opositores da prática eutanásica, é uma temeridade que se permita a alguém morrer com base em um quadro clínico que, a despeito da incurabilidade ou irreversibilidade atestada pelos médicos, pode vir a ser revertido ante os avanços diários da medicina e mudanças naturais que vão além da compreensão científica (Sa, 2002).

Os argumentos defendidos pelos opositores à eutanásia levam em conta, sobretudo, aspectos filosóficos, morais e religiosos. 0 argumento religioso relaciona-se ao princípio da sacralidade e inviolabilidade da vida (Pessini, 2001). O princípio no qual se fundamenta a norma moral que condena a eutanásia é o mesmo que condena o aborto provocado e a pena de morte: a vida é o primeiro direito de qualquer pessoa (Horta, 1999).

Hoje, o princípio da sacralidade é visto como o equilíbrio entre os dois extremos: o vitalismo físico, que defende o valor absoluto da manutenção da vida biológica, independentemente de outros valores como a independência, a autonomia, a dignidade, a prevenção de dor e a economia de recursos (o que pode levar a tratamentos abusivos); e o utilitarismo pessimista, que valoriza a vida a partir de seu uso social e defende seu término quando ela se torna frustrante, ou um peso (o que pode levar a abusos como a não utilização de tratamentos) (Pessini, 2001). Muitas vezes, a defesa da sacralidade da vida faz com que haja uma obsessão pela manutenção da vida biológica a qualquer custo, mesmo em condições de qualidade de vida extremamente prejudicada. Questiona-se sob que prisma a vida seria defendida por ser sacra: a meramente biológica ou a humana, que permite algum grau de realização pessoal e consciente (Sameshima, 2012). 
Siqueira-Batista e Schramm (2005) expõem outros argumentos contrários à prática da eutanásia, tais como: a desconfiança e o desgaste na relação médicopaciente (na impossibilidade da cura); a possibilidade da eutanásia não ser um ato altruísta, mas sim motivada por outras razões como heranças, pensões e seguros de vida; e a ocorrência de pressão psíquica pelo enfermo, de ser um "estorvo" para os familiares. Torna-se essencial também discernir o sofrimento intolerável de outras causas, como o estado depressivo; ter certeza sobre o diagnóstico, o prognóstico, a legalidade, o respeito à autonomia do doente, dos seus familiares, do médico e da sociedade (Batista, Barreto, Miranda e Garrafa, 2009).

Para os defensores da eutanásia, dois pontos são essenciais: a qualidade de vida e a autonomia. Uma das questões relacionadas à qualidade de vida é determinar qual o real significado de uma vida que vale a pena ser vivida e para quem deve ser dada a prerrogativa de decidir sobre ela. Segundo Batista, Barreto, Miranda e Garrafa (2009) a discussão bioética acerca da autonomia na terminalidade da vida é difícil, pois envolve também o paternalismo, a autoridade e a liberdade crítica. Outra linha de pensamento dos defensores da eutanásia a compara com situações em que a vida é retirada sem que haja crime, como no aborto permitido ou o homicídio em legitima defesa. 0 aborto em caso de gravidez resultante de estupro, com consentimento da gestante ou de seu representante legal, não é visto como ilícito, desde que o procedimento seja realizado por um médico (não necessariamente motivado por um sentimento de piedade ou compaixão). Assim, a vida intrauterina (que também é protegida constitucionalmente) é preterida em prol do princípio da dignidade humana e da proibição de tratamento desumano, priorizando o direito da gestante (Sameshima, 2012).

A conjectura em favor da eutanásia deve levar em consideração se a pessoa tem, ou deveria ter, o direito de decidir sobre que quantidade de sofrimento ela está preparada para aceitar e, quando esse limiar for atingido, se ela tem o direito de morrer. A expressão "direito de morrer" inclui o direito do paciente de não ser submetido a terapias inapropriadas ou inoportunas e o de receber medicamentos para aliviar a dor, mesmo sob o risco de abreviação da vida (Horta, 1999). Junges et. al. (2010) fazem a distinção entre o "direito de morrer dignamente", relacionado com o desejo de se ter uma morte natural, humanizada, sem o prolongamento da vida, e o "direito de morrer"como sinônimo de eutanásia ou de suicídio assistido. No direito de morrer dignamente, a morte digna do paciente poderá ocorrer em ambiente hospitalar ou residencial na presença dos entes queridos, familiares e pessoas do convívio, amparado pela equipe médica qualificada em cuidados paliativos.

Siqueira-Batista e Schramm (2009) analisaram os argumentos morais que sustentam a decisão de um (possível) agente da eutanásia em oferecer a outrem uma boa morte, tendo como referência as ferramentas da bioética da proteção. A compaixão, fundamento da moral, torna-se a matriz para a atitude de amparo ao outro, e se estabelece na compreensão de uma inquestionável situação de igualdade que é pertinente à vida, ou seja, nascer, sofrer e morrer. No entanto, a genuína experiência 
da compaixão torna-se difícil de ser colocada em prática no contexto de uma sociedade democrática complexa, laica e pluralista, contemporânea, composta por indivíduos detentores de direitos e deveres.

As discussões atuais acerca da eutanásia giram em torno de dois campos: os que se definem pró-vida e os pró-liberdade de escolha. No debate bioético, argumentos distintos também podem ser levantados de acordo com a categoria de eutanásia, havendo aqueles que condenam a eutanásia ativa, mas "aceitam" a eutanásia passiva, por exemplo, julgando legítimo que um enfermo se negue a passar por medidas terapêuticas extraordinárias (Pessini, 2001).

O debate sobre a bioética do fim da vida constitui um problema de saúde coletiva, já que o progressivo envelhecimento da população permite que um maior contingente de pessoas chegue à velhice, com consequente aumento das moléstias crônicodegenerativas e a um processo de morrer mais "prolongado", sujeito ao sofrimento. sendo assim, problemas de saúde pública são vivenciados, como a alocação de recursos para o tratamento desses enfermos, e a possibilidade de que as pessoas sejam excluídas de uma adequada assistência à saúde na proximidade da morte (Siqueira-Batista e Schramm, 2004).

De acordo com Batista, Barreto, Miranda e Garrafa (2009): "Na realidade brasileira, não há como falar em morte digna a uma população que sequer tem vida digna... A morte faz parte do processo de produção da vida econômica... A massificação dos serviços de saúde e o crescente sucateamento do setor público da saúde, a falta de regulamentação e fiscalização dos serviços privados, fizeram surgir graves problemas no atendimento, criando distanciamento nas relações médico-paciente, na proletarização da medicina e consequentemente descrédito nos profissionais e na crescente insegurança da população quanto aos cuidados e o respeito à dignidade da pessoa".

Pessini (2001) traz a tona al guns questionamentos relacionados à morte nos dias atuais: temos maior conhecimento biológico, que possibilita prognósticos precisos da morte, temos analgésicos poderosos para controlar a dor, temos máquinas mais sofisticadas para substituir e controlar órgãos; temos maior conhecimento psicológico para aliviar as ansiedades e o sofrimento de uma morte antecipada; no entanto, todo esse conhecimento não tornou a morte digna, pelo contrário, o processo do morrer se tornou mais problemático; difícil de prever e de lidar, fonte de dilemas éticos e escolhas dificílimas, geradoras de angústia, ambivalência e incertezas.

A presença massiva da tecnologia na medicina moderna é um fato necessário, no entanto, a dependência por essa tecnologia faz com que se deixe de lado a humanização nas práticas do cuidar, na manifestação de apreço, preocupação e soli- 
dariedade com os doentes. O "paradigma da cura"é governado pelos cuidados críticos e medicina de alta tecnologia; já no "paradigma do cuidado", o declínio e a morte são aceitos como parte da condição do ser humano, intensificando os esforços no sentido de amenizar o desconforto do morrer. Assim, o cuidar não é o prêmio de consolação pela cura não obtida, mas sim parte integral do tratamento da pessoa a partir de uma visão integral (Pessini, 2001).

Para Junges et. al. (2010), o processo de morte do sujeito deveria configurar-se como a morte ao seu tempo correto (ortotanásia), sem tratamentos desproporcionais (distanásia) e sem a abreviação (eutanásia). 0 direito de decidir sobre a própria morte, ou seja, de exercer a autonomia, deveria ser universal, e partir de uma moral secular e laica, como já o foi em muitas sociedades da antiguidade.

\section{Considerações finais}

Nos dias de hoje, no âmbito assistencial da saúde, muitas vezes trata-se a doença e esquece-se de tratar o doente, de forma holística, buscando não somente o seu bem estar físico, mas também o psíquico e o emocional. Preserva-se a vida a qualquer custo, independente de sua qualidade, em um processo onde os efeitos do tratamento muitas vezes podem ser mais nocivos do que os da própria doença. Neste contexto, questiona-se até quando o poder de escolha e a autonomia do paciente continuarão a ser ignorados pelos profissionais de saúde que o estão "tratando". E se a medicina não mais travasse uma luta sem fim contra a morte? E se passasse a aceitar a morte como parte da vida biológica da pessoa, como um limite que não pode ser vencido, e uma doença que não pode ser curada? Sem dúvida nenhuma, o papel da medicina seria transformado, através da aceitação e da compreensão do processo de viver e de morrer, proporcionando não somente uma morte digna, mas também uma vida digna aos pacientes.

Trabalho desenvolvido na Universidade de Brasilia, apresentado para conclusão da disciplina Fundamentos da Bioética.

\section{Referências}

1. Batista KT. Terminalidade da vida: Reflexões bioéticas sobre a distanásia (Monografia). Brasília, Universidade de Brasília; 2007.

2. Batista KT, Barreto SC, Miranda A, Garrafa V. Reflexões bioéticas nos dilemas do fim da vida. Brasília Med 2009; 46 (1): 54-62.

3. Boeuri CA. Humanização na Unidade de Terapia Intensiva. In: Associação Brasileira de Fisioterapia Cardiorrespiratória e Fisioterapia em Terapia Intensiva; Guimarães FS, Martins JA, diretores acadêmicos. PROFISIO Programa de Fisioterapia em Terapia Intensiva Adulto: Ciclo 1. Porto Alegre: Artmed Panamericana; 2010. p.57-73. (Sistema de Educação Continuada à Distância, v. 2).

4. Bomfim LR. Eutanásia: questões éticas e jurídico-penais relevantes. Revista do CEPEJ. (Salvador), 2009; 11, p.303. 
5. Borges RCB. Direito de morrer dignamente: eutanásia, ortotanásia, consentimento informado, testamento vital, análise constitucional e penal e direito comparado. In: SANTOS, Maria Celeste Cordeiro Leite dos (org.). Biodireito: ciência da vida, os novos desafios. São Paulo: RT, 2001

6. Conselho Federal de Medicina. Resolução n 1.480, de 8 de agosto de 1997. Disponível em: http://www.portalmedico.org.br/resolucoes/cfm/1997/1480_1997.htm. Acesso em 18/05/2016.

7. BRASIL. Decreto-Lei no 2.848, 1940. Código Penal Brasileiro. Artigo 121. In BRASIL. Código penal (1940). $5^{\mathrm{a} e d . ~ S a ̃ o ~ P a u l o: ~ S a r a i v a, ~} 2011$.

8. Conselho Federal de Medicina. Resolução CFM No 1.805/2006 (Publicada no D.O.U., 28 nov. 2006, Seção I, pg. 169). Disponível em http://www.portalmedico.org.br/resolucoes/cfm/2006/1805_2006.htm. Acessado em 19/05/2016.

9. Buzaglo SA. Eutanásia. Carta Mensal. Rio de Janeiro, 2006; (52): 615; p.7.

10. UNESCO. DECLARAÇÃO UNIVERSAL DA BIOÉTICA E DIREITOS HUMANOS (DHBDH), 2005. Disponível em: http://unesdoc.unesco.org/images/0014/001461/146180por. pdf. Acesso em: 18/05/2016.

11. Engelhardt HT. Fundamentos da bioética, $2^{a}$ edição, Edições Loyola, 2004.

12. Farah E. Eutanásia, ortotanásia e distanásia - reflexões básicas em face da ciência médica e do Direito. Revista do Instituto dos advogados de São Paulo. São Paulo, 2011; 14(28): 170.

13. Ferraz OLM. Eutanásia e homicídio - matar e deixar morrer: uma distinção válida? Revista de Direito sanitário. São Paulo, 2001; 2 (2).

14. Herzog E. Psyche and Tod. Wandlungen des Todesbildes in Mythos and in den Tritumen heutiger Menschen, Zurique, 1960 (tradução inglesa: Psyche and death, Putnam, 1967). In: Illich I. A expropriação da saúde: nêmesis da Medicina. Tradução de José Kosinski de Cavalcanti. Rio de Janeiro; 3a edição, Editora Nova Fronteira, 1975.

15. Horta MP. Eutanásia: problemas éticos da morte e do morrer. Revista bioética, 1999;7(1):59-64.

16. Illich I. A expropriação da saúde: nêmesis da medicina. Tradução de José Kosinski de Cavalcanti. Rio de Janeiro; $3^{a}$ edição, Editora Nova Fronteira, 1975.

17. Junges JR, Cremonese C, Oliveira EA, Souza KM, Backwa V. Reflexões legais e éticas sobre o final da vida: uma discussão sobre a ortotanásia. Revista Bioética 2010; 18 (2): 275 - 88.

18. Kovacs MJ. Bioética nas questões da vida e da morte. Psicologia USP, 2003, 14(2), 115-167.

19. Lepargneur H. Bioética da eutanásia: argumentos éticos em torno da eutanásia. Bioética 1999; 7: 41-8.

20. Lima Neto LI. A legalização da eutanásia no Brasil. Revista Jus Navigandi 2003; 8(81). Disponível em: <https://jus.com.br/artigos/4217>. Acesso em 18/052016.

21. Lopes AC, Lima CAS, Santoro LF. Eutanásia, ortotanásia e distanásia - aspectos médicos e jurídicos. São Paulo: Atheneu, 2011. p.60.

22. Magalhães CBA, Vasconcelos TB, Ferreira SS, Neto JMA, Sales RP, Vasconcelos RS, Macena RHM. Current issues on bioethics in intensive care: an integrative narrative review. UNIFOR-MG 2013; 8 (2):73-86.

23. Maranhão JLS. O que é morte? $4^{a}$ ed. São Paulo: Brasiliense, 1998. p.20-21. 
24. Moritz RD. Os profissionais de saúde diante da morte e do morrer. Bioética. 2005; 13:51. In: Batista KT, Barreto SC, Miranda A, Garrafa V. Reflexões bioéticas nos dilemas do fim da vida. Brasília Med 2009; 46 (1): 54-62

25. Moura EM. Eutanásia, ortotanásia e doação de órgãos. Revista de Direito Constitucional e Internacional. São Paulo, 2007; 15(58): 40.

26. Pessini L. Distanásia: até quando prolongar a vida? São Paulo: Editora São Camilo/Edições Loyola; 2001. 23. Pessini L. Eutanásia: por que abreviar a vida? São Paulo: Editora do Centro Universitário de São Camilo, 2004. p. 218.

27. República de Colômbia. Ministerio de Salud y Protección Social. Resolución nº 1216 de 2015. Disponível em: http://www.dmd.org.co/pdf/Eutanasia_resolucion-1216-de-2015. pdf. Acesso em 18/05/2016.

28. Reta A, Grezzi O. Código Penal de la República Oriental del Uruguay. $4^{\text {aed }}$ ed. Montevideo: Fundación de Cultura Univerrsitária, 1996.

29. Sá LHLA. Eutanásia, ortotanásia e legislação penal. Direito e Paz. São Paulo, 2002; 4(6):232.

30. Sameshima MF. A eutanasia no ordenamento juridico penal brasileiro (Monografia). Brasília, Centro Universitário de Brasília - UNICEUB; 2012.

31. Santoro LF. Morte digna - o direito do paciente terminal. Curitiba: Juruá, 2011. p. 133.

32. Siqueira-Batista R, Schramm FR. Conversações sobre a "boa morte": o debate bioético acerca da eutanásia. Cad. Saúde Pública (Rio de Janeiro), 2005; 21 (1):111-119.

33. Siqueira-Batista R, Schramm FR. A eutanásia e os paradoxos da autonomia. Ciênc. Saúde Coletiva. 2008; 13(1): 207-21.

34. Siqueira-Batista R, Schramm FR. A bioética da proteção e a compaixão laica: o debate moral sobre a eutanásia. Ciênc. Saúde Coletiva, 2009; 14 (4).

35. Siqueira-Batista R, Schramm FR. Eutanásia: pelas veredas da morte e da autonomia. Ciênc. Saúde Coletiva, 2004; 9 (1).

36. Vasconcelos TJQ, Inamura NR, Villar HCEC. Impacto da Resolução CFM 1.805/06 sobre os médicos que lidam com a morte. Rev. bioét 2011; 19(2): 501 - 21

37. Villas-Bôas ME. Da eutanásia ao prolongamento artificial: aspectos polêmicos na disciplina jurídico-penal do final de vida. Rio de Janeiro: Forense, 2005. p.18-19.

Recebido em: 22/08/2016 Aprovado em: 07/11/2016. 